\title{
Ligamentum Flavum Hematoma in the Lumbar Spine -Case Report-
}

\author{
Junichi MIZUnO, Hiroshi NAKAGAWA, Tatsushi InOUE, \\ and Yoshio HASHIZUME* \\ Department of Neurological Surgery, and *Institute of Medical Science for Aging, \\ Aichi Medical University, Aichi
}

\begin{abstract}
A previously healthy 45-year-old woman presented with ligamentum flavum hematoma manifesting as radicular leg pain. Neurological examination findings were consistent with L-5 root compression. An old hematoma inside the degenerated ligamentum flavum was drained. The cyst showed no connection to the facet joint. Complete resection of the mass was performed, resulting in excellent pain relief. The most common cystic lesion in the lumbar spine is synovial cyst associated with the facet joints, but ligamentum flavum hematoma should be included in the differential diagnosis. The preoperative diagnosis can be based on computed tomography and magnetic resonance imaging findings of degenerative thickening of the ligamentum flavum associated with a fluid component.
\end{abstract}

Key words: ligamentum flavum, hematoma, cyst, disc herniation, lumbar spine

\section{Introduction}

Lumbar radiculopathy may be caused by a soft tissue mass, most commonly herniated intervertebral disc. Cysts in the epidural space, though less common, can manifest as symptoms similar to those caused by disc herniation. Epidural cysts are usually synovial cysts or ganglion cysts associated with the facet joints. ${ }^{5,8,9)}$ Ligamentum flavum hematoma is an extremely rare cause of nerve root compression. We treated a 45-year-old woman with a ligamentum flavum hematoma compressing the nerve root at the left L4-5.

\section{Case Report}

A 45-year-old woman experienced severe shooting pain from the left gluteus muscle to the posterolateral region of the left thigh when she lifted a dinner table. She underwent conservative therapy prescribed by a local physician for 3 months, but her symptom did not improve. On admission, neurological examination found $4 / 5$ strength in the left tibialis anterior and the left extensor hallucis longus muscles, and hypesthesia in the left L-5 and S-1 sensory distributions. Deep tendon reflexes in the

Received May 28, 2004; Accepted October 25, 2004

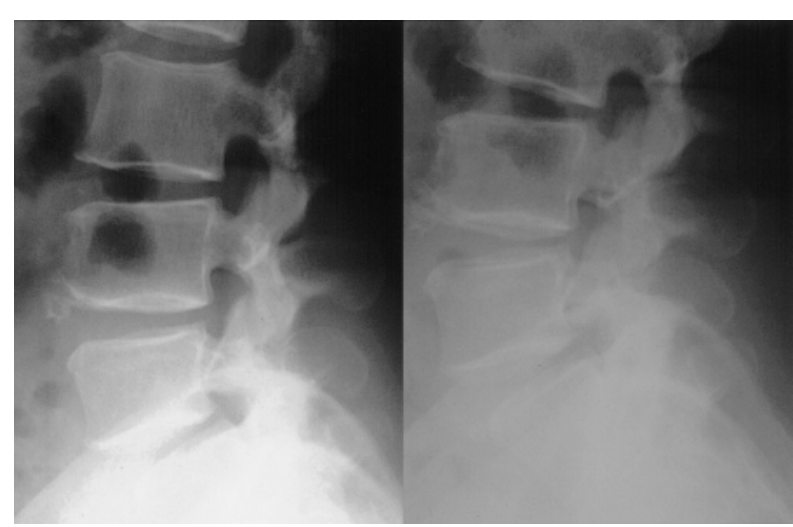

Fig. 1 Lateral radiographs in flexion-extension revealing no significant instability.

lower extremities, and bladder and bowel function were normal. The straight leg-raising test was positive at 45 degrees on the left. Lateral radiography in flexion-extension showed no significant instability (Fig. 1). Computed tomography (CT) revealed a unilateral hypertrophic ligamentum flavum containing a round, slightly low-density mass near the juxtaarticular region (Fig. $2 \mathrm{~A}$ ). $\mathrm{T}_{1^{-}}$ weighted magnetic resonance (MR) imaging revealed an isointense lesion associated with a diffusely thickened ligamentum flavum at L4-5 on the left, and 


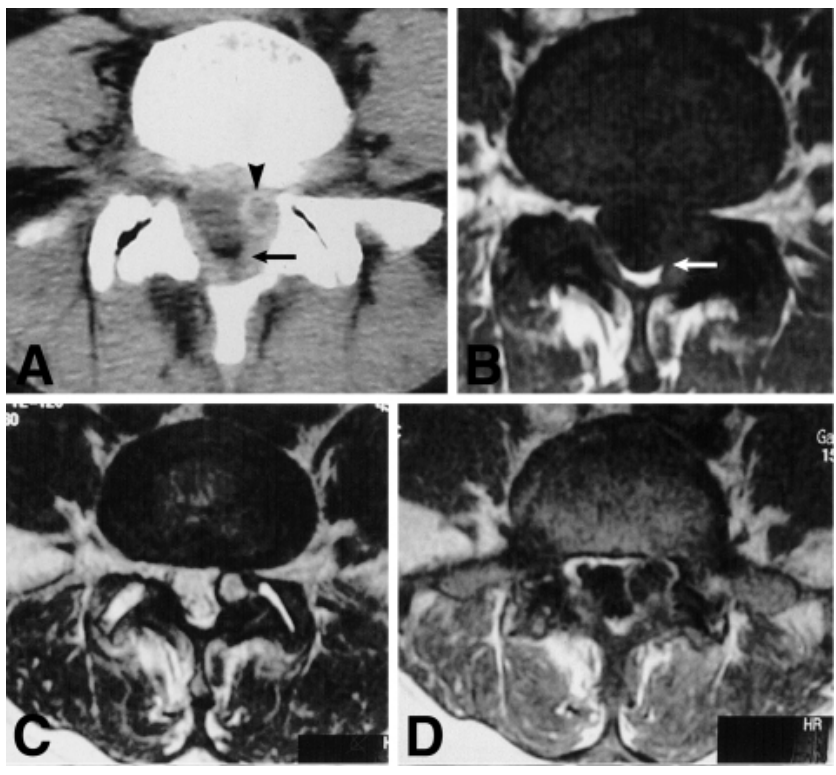

Fig. 2 (A) Computed tomography scan revealing fluid collection (arrowhead) associated with bulging of the ligamentum flavum (arrow) at the juxtaarticular portion. (B) $\mathrm{T}_{1}$-weighted magnetic resonance (MR) image revealing an isointense mass associated with a hypertrophic ligamentum flavum (arrow) occupying the posterolateral portion of the spinal canal at L4-5. (C) $T_{2}$-weighted $M R$ image showing a well-demarcated hyperintense lesion. (D) $T_{1}$-weighted $M R$ image with gadolinium-diethylenetriaminepenta-acetic acid showing peripheral enhancement of the mass.

$\mathrm{T}_{2}$-weighted $\mathrm{MR}$ imaging revealed a hyperintense lesion (Fig. 2B, C). The peripheral portion of the mass was well enhanced after intravenous administration of gadolinium-diethylenetriaminepenta-acetic acid (Gd-DTPA) (Fig. 2D).

The patient underwent surgery for decompression of the spinal canal and resection of the lesion. After L4-5 partial laminectomy, the thickened ligamentum flavum was incised. The ligamentum flavum had partially adhered to the dural theca, and contained a dark brownish fluid which was aspirated. The remaining thickened ligamentum flavum was removed. There was no calcification or ossification of the ligamentum flavum. After resection of the mass, the L-5 nerve root became mobile. As the facet joint remained intact, no fixation was added. The operative findings were consistent with ligamentum flavum hematoma compression of the L-5 nerve root.

Histological examination showed degeneration of the ligamentous fibers with hyalinoid changes.
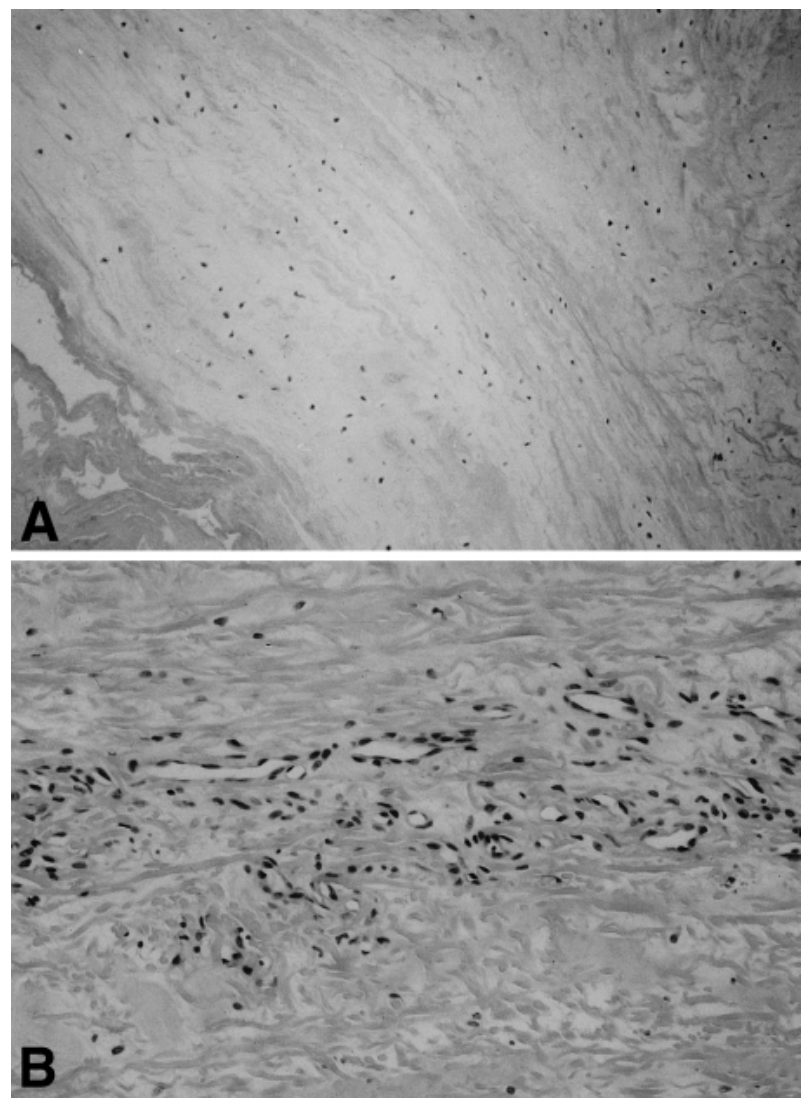

Fig. 3 Photomicrographs of the surgical specimen showing thickening and degeneration of the collagenous fibers and hyalinoid changes of the ligamentum flavum (A: hematoxylineosin stain, original magnification $\times 25$ ) and proliferation of small vessels (B: hematoxylin-eosin stain, original magnification $\times 30$ ).

Proliferation of small vessels was seen in the degenerated ligamentum flavum, but no vascular anomalies were observed (Fig. 3).

The patient's postoperative course was uneventful. Immediately after surgery, she became asymptomatic except for slight numbness in the left L-5 region. Follow-up examination 12 months later found she was neurologically intact and symptomfree (Fig. 4).

\section{Discussion}

Ligamentum flavum hematoma is very rare, with only six reported cases (Table 1).2,3,7,10,12) All patients were men aged from the 40 s to the 70 s. Our patient is the first female patient, and her age was in the $40 \mathrm{~s}$. All patients had a history of minor trauma, and the ligamentum flavum hematoma was located in the 
lumbar spinal canal. All patients experienced acute onset of shooting leg pain after minor trauma. The pathogenesis of ligamentum flavum hematoma is considered to originate from minor trauma such as flexion or extension motion, physical exercises, or heavy lifting involving the back. Transmission of increased intra-abdominal pressure after minor trauma to the very small, thin-walled blood vessels in the degenerated ligamentum flavum might lead to rupture of these vessels. ${ }^{7)}$ Disruption of the vessels in the degenerated ligamentum flavum may occur due to excessive stretching force on the back. ${ }^{10)}$ In the present case, we speculate that rupture of the

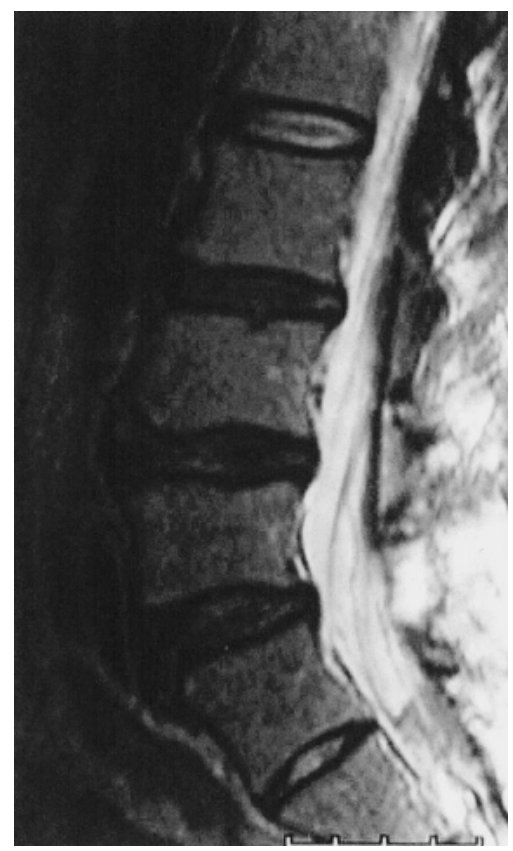

Fig. 4 Postoperative $\mathrm{T}_{2}$-weighted magnetic resonance image showing good decompression of the L-5 root with total removal of the ligamentum flavum hematoma. proliferated small vessels in the degenerated and hypertrophic ligamentum flavum occurred after lifting a dinner table, causing acute leg pain by entrapping the L-5 root with an old hematoma in the ligament which remained unabsorbed and thus produced the persistent symptoms.

The differential diagnosis of ligamentum flavum hematoma includes synovial cyst, ganglion cyst, and other cystic lesions. ${ }^{1,4,6,11)}$ MR imaging typically shows a well-circumscribed extradural cystic lesion as isointense or slightly hypointense with peripheral enhancement after administration of Gd-DTPA on $\mathrm{T}_{1}$-weighted images, and hyperintense on $\mathrm{T}_{2}$-weighted images. Synovial cysts, ganglion cysts, and ligamentum flavum cysts typically occur in the posterolateral spinal canal or lateral recess, so differentiation is difficult based on only the shape or intensity of the cysts on preoperative neuroimaging. ${ }^{8)}$ CT and MR imaging in our case showed that thickening of the ligamentum flavum associated with a fluid component is suggestive of ligamentum flavum hematoma. Hypertrophic and hyalinoid changes of the ligamentous tissue contain proliferations of small vessels as part of the degenerative processes. These small vessels may be the origin of hemorrhage under high abdominal pressure, as in the present case. ${ }^{7,10)}$ Therefore, we emphasize that degenerative thickening of the ligamentum flavum associated with a fluid component on CT or MR imaging is indicative of ligamentum flavum hematoma.

Ligamentum flavum hematoma is typically treated surgically with partial laminectomy, excision of the degenerated ligamentum flavum, and removal of the hematoma. Resection of the hematoma and the ligamentum flavum, and posterior fixation has been performed. ${ }^{2,3)}$ However, we suggest that microsurgical laminectomy and medical facetectomy provide an adequate operating view to remove ligamentum flavum hematoma, making additional fixation unnecessary. Since ligamentum flavum hematoma has

Table 1 Cases of ligamentum flavum hematoma

\begin{tabular}{|c|c|c|c|c|c|}
\hline Author (Year) & $\begin{array}{l}\text { Age (yr), } \\
\text { Sex }\end{array}$ & Level & Etiology & Treatment & Outcome \\
\hline Sweasey et al. $(1992)^{10)}$ & $\begin{array}{l}43, \mathrm{M} \\
60, \mathrm{M}\end{array}$ & $\begin{array}{l}\text { L4-5 } \\
\text { L2-3 }\end{array}$ & $\begin{array}{l}\text { minor back injury } \\
\text { stepped up onto box }\end{array}$ & $\begin{array}{l}\text { total resection } \\
\text { total resection }\end{array}$ & $\begin{array}{l}\text { excellent } \\
\text { excellent }\end{array}$ \\
\hline Cruz-Conde et al. $(1995)^{2)}$ & $67, \mathrm{M}$ & L4-5 & physical exertion & $\begin{array}{l}\text { total resection with } \\
\text { fixation }\end{array}$ & excellent \\
\hline Minamide et al. (1999) ${ }^{7)}$ & $76, \mathrm{M}$ & L3-4 & stood upon a train seat & total resection & excellent \\
\hline Present case & $45, F$ & L4-5 & lifted a table & total resection & excellent \\
\hline
\end{tabular}


no attachment to the facet joints, the stability of the lumbar spine can be regarded as intact. After internal decompression to evacuate the hematoma, the ligamentum flavum collapses and separation of the dural theca is easy. Surgery resulted in excellent outcomes in all patients.

\section{References}

1) Baker JK, Hanson GW: Cyst of the ligamentum flavum. Spine 19: 1092-1094, 1994

2) Cruz-Conde R, Berjano P, Buitron Z: Ligamentum flavum hematoma presenting as progressive root compression in the lumbar spine. Spine 20: 1506-1509, 1995

3) Hirakawa K, Hanakita J, Suwa H, Matsushita N, Oda M, Muro H, Fukushima T: A post-traumatic ligamentum flavum progressive hematoma. Spine 25: $1182-1184,2000$

4) Jackson DE, Atlas SW, Mani JR, Norman D: Intraspinal synovial cysts: MR imaging. Radiology 170: 527-530, 1989

5) Lyons MK, Atkinson JL, Wharen RE, Deen HG, Zimmerman RS, Lemens SM: Surgical evaluation and management of lumbar synovial cysts: The Mayo Clinic experience. J Neurosurg 93 (Suppl 1): 53-57, 2000

6) Mahallati H, Wallace CJ, Hunter M, Bilbao JM, Clark AW: MR imaging of a hemorrhagic and granuloma- tous cyst of the ligamentum flavum with pathologic correlation. AJNR Am J Neuroradiol 20: 1166-1168, 1999

7) Minamide A, Yoshida M, Tamaki T, Natsumi K: Ligamentum flavum hematoma in the lumbar spine. $J$ Orthop Sci 4: 376-379, 1999

8) Onofrio BM, Mih AD: Synovial cysts of the spine. Neurosurgery 22: 642-647, 1988

9) Sabo RA, Tracy PT, Weinger JM: A series of 60 juxtafacet cysts: Clinical presentation, the role of spinal instability, and treatment. J Neurosurg 85: 560-565, 1996

10) Sweasey TA, Coester HC, Rawal H, Blavas M, McGillicuddy JE: Ligamentum flavum hematoma. Report of two cases. J Neurosurg 76: 534-537, 1992

11) Vernet O, Fankhauser H, Schnyder P, Deruaz JP: Cysts of the ligamentum flavum: report of six cases. Neurosurgery 29: 277-283, 1991

12) Yuceer N, Baskaya MK, Smith P, Willis BK: Hematoma of the ligamentum flavum in the lumbar spine: Case report. Surg Neurol 53: 598-600, 2000

Address reprint requests to: J. Mizuno, M.D., Department of Neurological Surgery, Aichi Medical University, 21 Karimata, Yazako, Nagakute-cho, Aichi-gun, Aichi 480-1195, Japan.

e-mail: jmizuno@amugw.aichi-med-u.ac.jp 